\title{
The importance of interstitial particle scavenging by cloud droplets in shaping the remote aerosol size distribution and global aerosol-climate effects
}

\author{
J. R. Pierce ${ }^{1,2}$, B. Croft ${ }^{2}$, J. K. Kodros ${ }^{1}$, S. D. D’Andrea ${ }^{1}$, and R. V. Martin ${ }^{2}$ \\ ${ }^{1}$ Department of Atmospheric Science, Colorado State University, Fort Collins, CO, USA \\ ${ }^{2}$ Department of Physics and Atmospheric Science, Dalhousie University, Halifax, NS, Canada
}

Correspondence to: J. R. Pierce (jeffrey.pierce@ colostate.edu)

Received: 11 January 2015 - Published in Atmos. Chem. Phys. Discuss.: 26 February 2015

Revised: 12 May 2015 - Accepted: 15 May 2015 - Published: 5 June 2015

\begin{abstract}
In this paper, we investigate the coagulation of interstitial aerosol particles (particles too small to activate to cloud droplets) with cloud drops, a process often ignored in aerosol-climate models. We use the GEOS-Chem-TOMAS (Goddard Earth Observing System-Chemistry TwO-Moment Aerosol Sectional) global chemical transport model with aerosol microphysics to calculate the changes in the aerosol size distribution, cloud-albedo aerosol indirect effect, and direct aerosol effect due to the interstitial coagulation process. We find that inclusion of interstitial coagulation in clouds lowers total particle number concentrations by 15 $21 \%$ globally, where the range is due to varying assumptions regarding activation diameter, cloud droplet size, and ice cloud physics. The interstitial coagulation process lowers the concentration of particles with dry diameters larger than $80 \mathrm{~nm}$ (a proxy for larger CCN) by $10-12 \%$. These $80 \mathrm{~nm}$ particles are not directly removed by the interstitial coagulation but are reduced in concentration because fewer smaller particles grow to diameters larger than $80 \mathrm{~nm}$. The global aerosol indirect effect of adding interstitial coagulation varies from +0.4 to $+1.3 \mathrm{~W} \mathrm{~m}^{-2}$ where again the range depends on our cloud assumptions. Thus, the aerosol indirect effect of this process is significant, but the magnitude depends greatly on assumptions regarding activation diameter, cloud droplet size, and ice cloud physics. The aerosol direct effect of the interstitial coagulation process is minor $\left(<0.01 \mathrm{~W} \mathrm{~m}^{-2}\right)$ due to the shift in the aerosol size distribution at sizes where scattering is most effective being small. We recommend that this interstitial scavenging process be considered in aerosol models when the size distribution and aerosol indirect effects are important.
\end{abstract}

\section{Introduction}

Atmospheric aerosol particles of both anthropogenic and natural origin have important effects on human health (Dockery et al., 1993), visibility (Malm et al., 2000) and climate (Boucher et al., 2013). The magnitude of these aerosol effects depend on the concentration, composition and size of the particles. The particles may affect climate directly by scattering and absorbing solar radiation (the aerosol direct effect; Charlson et al., 1992) and indirectly by acting as cloud condensation nuclei (CCN, the seeds for cloud-droplet formation) and affecting cloud radiative properties (the aerosol indirect effect; Twomey, 1974; Albrecht, 1989). Uncertainties in these aerosol-climate effects are among the leading uncertainties in recent climate forcing changes (Boucher et al., 2013).

The particle size and composition distribution is shaped in the atmosphere by primary emissions of particles, removal of particles through dry and wet deposition, coagulation, aerosol- and cloud-phase chemistry, and condensation from and evaporation to the vapor phase. In remote regions of the atmosphere, away from major anthropogenic sources of particles (e.g., remote oceans and polar regions), understanding the removal processes becomes increasingly important in simulating aerosol-climate effects (Carslaw et al., 2013; Lee et al., 2013; Croft et al., 2014). Lee et al. (2013) show that uncertainties in dry and wet deposition were ranked first and third, respectively, as the largest contributors to CCN uncertainty in clean remote regions (out 27 uncertain parameters investigated). As aerosol-climate effects are strongly sensitive to $\mathrm{CCN}$ concentrations in remote regions due to the 
low baseline $\mathrm{CCN}$ concentrations, particle removal mechanisms must be well represented in aerosol-climate simulations (Carslaw et al., 2013).

Coagulation is an important removal mechanism of particle number and it moves particle mass towards larger particle sizes. Brownian coagulation, the process where particles collide by diffusion through air, is the dominant coagulation mechanism for aerosol particles (Seinfeld and Pandis, 2006). The coagulation kernel, the rate constant for coagulation between particles of two different sizes, increases as the diameter of the smaller particle decreases (increasing the diffusivity of the smaller particle) and as the larger particle increases (increasing the size of the target for the smaller, diffusing particle). The Brownian coagulation kernel reaches a minimum when the particles have the same size.

In clouds, $\mathrm{CCN}$-sized particles (particles with dry diameters larger than $30-100 \mathrm{~nm}$ depending on particle composition and cloud conditions) will activate into cloud droplets, and their diameters will typically grow to 5-20 $\mu \mathrm{m}$ (Rogers and Yau, 1989). The smaller particles will not activate and will continue to have wet diameters below $\sim 100 \mathrm{~nm}$ in the cloud. These unactivated particles are referred to as interstitial particles. The increase in size of $\mathrm{CCN}$ to cloud droplets will enhance the Brownian coagulation rate between the $\mathrm{CCN}$ particles (now cloud droplets) and the interstitial particles. Other effects, such as thermophoresis, diffusiophoresis, turbulence and electrical effects (e.g., charged droplets and/or particles) may also increase the collection of interstitial particles by cloud droplets but are less well understood than Brownian coagulation (Pruppacher and Klett, 1997). Furthermore, if cloud droplets (or ice crystals in ice clouds) grow to diameters beyond $\sim 20 \mu \mathrm{m}$, the droplets/crystals will have non-trivial fall speeds relative to the interstitial particles, and gravitational collection of the particles will also contribute to and may dominate coagulation (Rogers and Yau, 1989).

In the case of non-precipitating clouds, the cloud droplets will generally not grow to diameters beyond $20 \mu \mathrm{m}$, and Brownian coagulation will dominate the coagulation between droplets and interstitial particles. Any coagulation between the droplets and the interstitial particles will lead to a reduction of interstitial particle number and an increase in the size of the $\mathrm{CCN}$-sized particles after the cloud dries. This coagulation may impact climate in two ways: (1) the removed interstitial particles that may have otherwise grown to $\mathrm{CCN}$ sizes via condensation and increased $\mathrm{CCN}$ concentrations (Pierce and Adams, 2007; Westervelt et al., 2013, 2014). Thus, this coagulation may lower CCN concentrations and lead to a warming through a reduction in the magnitude of the aerosol indirect effect. (2) The shift of particle mass from the smaller, interstitial sizes to the larger sizes of the activated particles may result in a change in the mass scattering and absorption efficiencies of the particles and change the magnitude of the aerosol direct effect (Seinfeld and Pandis, 2006).
In the case of precipitating clouds, the coagulation of particles below clouds by falling drops via gravitational collection directly contributes to wet scavenging/deposition of these particles. The gravitational collection of particles below clouds by precipitation is typically included in global aerosol models and has been investigated in earlier studies of collection efficiency (Greenfield, 1957; Klett and Davis, 1973; Lin and Lee, 1975; Schlamp et al., 1976; Wang et al., 1978; Hall, 1980), parameterizations (Slinn, 1984; Jung and Lee, 1997; Croft et al., 2009; Wang et al., 2014) and recent reviews (Zhang et al., 2013), so we will not focus on these effects in this paper. Brownian coagulation of cloud droplets and interstitial particles still occurs in precipitating clouds, but the collecting cloud droplets will only be wet scavenged/deposited if they are converted into a precipitation drop.

Brownian coagulation of interstitial particles with cloud droplets is often ignored in aerosol models, and we are not aware of any papers that have quantified the importance of this process on aerosol direct and indirect effects on the global scale. Hoose et al. (2008) included Brownian coagulation of interstitial particles with cloud droplets, along with other aerosol-cloud interactions, in the ECHAM-HAM climate model with online aerosol and cloud microphysics. While Hoose et al. (2008) provides zonal mass budgets for how this coagulation impacts the aerosol size modes in their model, they do not explicitly quantify the impact of this coagulation on global aerosol size distributions and climate. The Brownian coagulation of interstitial particles with cloud droplets is also included in the MIRAGE model (Easter et al., 2004; Ghan et al., 2006) but, like ECHAM-HAM, we are not aware of a detailed evaluation of this process. Finally, this process is included in HADAM4 (Jones et al., 2001), but this is a mass-only model and does not consider the evolution of the aerosol size distribution. To our knowledge, the Brownian coagulation between interstitial particles and cloud droplets has not previously been considered in many of the other global aerosol microphysics models, including GEOS-Chem-TOMAS ((Goddard Earth Observing System-Chemistry TwO-Moment Aerosol Sectional); D'Andrea et al., 2013; Pierce et al., 2013; Trivitayanurak et al., 2008), GISS-TOMAS (Adams and Seinfeld, 2002; Pierce and Adams, 2009), GLOMAP (Spracklen et al., 2005a, b, 2008; Mann et al., 2012), GLOMAP-Mode (Mann et al., 2010, 2012; Lee et al., 2013), GEOS-Chem-APM (Yu and Luo, 2009; Yu, 2011) and IMPACT (Herzog et al., 2004; Wang and Penner, 2009).

In this paper, we estimate the effects of Brownian coagulation of interstitial particles with cloud droplets in shaping the aerosol size distribution and aerosol-climate effects, globally. Additionally, we compare the simulated size distributions with and without interstitial coagulation to measurements at 21 sites globally to determine if the inclusion of this coagulation improves our simulated size distributions. We only consider Brownian coagulation between the interstitial particles 
and cloud droplets, and we do not consider thermophoresis, diffusiophoresis, turbulence, or electrical effects. These other effects will change the rate of coagulation of the interstitial particles in the accumulation-mode size range with the cloud droplets, and will have less influence on the smaller particles relative to the effects of Brownian diffusion. In the following section, we describe the GEOS-Chem-TOMAS global chemical transport model with online aerosol microphysics used in this study, the modifications we made to the model, and the various model simulations. In Sect. 3, we provide the results and analysis of our model simulations estimating the effect of interstitial particle coagulation by cloud droplets, and we compare our simulated results to measurements. Finally, we provide conclusions in Sect. 4.

\section{Methods}

\subsection{GEOS-Chem-TOMAS overview}

In this paper, we simulate global aerosol size distributions using the GEOS-Chem-TOMAS model, which is a coupling of the GEOS-Chem global chemical transport model (www.geos-chem.org, Bey et al., 2001) with the TOMAS microphysics scheme (Adams and Seinfeld, 2002; Lee and Adams, 2012). In this work, model simulations use GEOSChem version 9.02 at $4^{\circ} \times 5^{\circ}$ resolution globally with 47 layers extending from the surface to $0.01 \mathrm{hPa}$. Modeled meteorology is taken from the National Aeronautics and Space Administration (NASA) Global Modeling and Assimilation Office (GMAO) Goddard Earth Observing System version 5 (GEOS-5) assimilated meteorology product. All simulations use year 2012 meteorology and emissions following a 3month spin-up at the end of 2011. GEOS-Chem includes simulation of 50 gas-phase species including aerosol precursor gases such as $\mathrm{SO}_{2}$ and $\mathrm{NH}_{3}$.

TOMAS in this work tracks the number and mass of particles within each of 15 size sections. The first 13 size sections are logarithmically spaced and span diameters from approximately $3 \mathrm{~nm}$ to $1 \mu \mathrm{m}$, and the 2 final size sections span $1-$ $10 \mu \mathrm{m}$ (Lee and Adams, 2012). Particle composition includes sulfate, ammonia, sea spray, hydrophilic organics, hydrophobic organics, internally mixed black carbon, externally mixed black carbon, dust and water. Particle nucleation is estimated using the ternary scheme $\left(\mathrm{H}_{2} \mathrm{SO}_{4}+\mathrm{NH}_{3}+\mathrm{H}_{2} \mathrm{O}\right)$ of Napari et al. (2002) with nucleation rates scaled by $10^{-5}$, which showed good agreement versus observations in Westervelt et al. (2013) and the binary $\left(\mathrm{H}_{2} \mathrm{SO}_{4}+\mathrm{H}_{2} \mathrm{O}\right)$ nucleation scheme of Vehkamäki et al. (2012) in the regions with $\mathrm{NH}_{3}$ mixing ratios below the Napari et al. (2002) threshold. Particle sizes below $3 \mathrm{~nm}$ are approximated using the Kerminen et al. (2004) scheme, which has been evaluated in TOMAS in Lee et al. (2013). Secondary organic aerosol (SOA) includes both a biogenic contribution and an anthropogenic (or anthropogenically enhanced yields of biogenic SOA) contribu- tion and is considered to be non-volatile for the condensation parameterization as in D'Andrea et al. (2013). Emissions in GEOS-Chem-TOMAS are described in detail in Stevens and Pierce (2014).

Coagulation between particles in GEOS-Chem-TOMAS occurs using the Brownian coagulation scheme of Fuchs (1964). Prior to this work, the particle size for the coagulation parameterization was found using the grid-box-mean relative humidity for water uptake (capped at $99 \%$ ) both in and out of clouds. Thus, in clouds, previous versions did not account for Brownian coagulation of interstitial aerosols with particles that have grown to cloud droplet size. This previous model version that lacked coagulation between interstitial particles and cloud droplets will be our base assumption for comparison in this paper.

\subsection{Brownian coagulation between interstitial particles with cloud droplets}

In this work, we add Brownian coagulation between interstitial particles and particles that are assumed to have activated and grown to cloud droplet size. In the GEOS-5 assimilated meteorological fields, model grid boxes are divided into cloudy fractions and non-cloudy fractions. For the cloudy fraction of the grid box, we assume that all particles above a certain size threshold activated into cloud droplets (this size threshold is varied in different simulations described below). We assume that the activated aerosols have a fixed wet size equal to the assumed cloud droplet size, which is varied between simulations, described below. The coagulation kernel is then calculated between all particle size-bin combinations regardless of whether the particles in the bin are activated or not. Similarly, we calculate the coagulation kernel for the non-cloudy portion of the grid box for all size-bin combinations assuming that all bins are of non-activated wet size. The grid-box-mean coagulation rate between any two size bins is then calculated as follows:

$$
\begin{aligned}
J_{i, j} & =\left(1-f_{\text {cloudy }}\right) K_{\text {clear } ; i, j} N_{i} N_{j} \\
& +f_{\text {cloudy }} K_{\text {cloudy } ; i, j} N_{i} N_{j},
\end{aligned}
$$

where $J_{i, j}$ is the coagulation rate between particles in bins $i$ and bin $j, f_{\text {cloudy }}$ is the fraction of the grid box that is cloudy, $K_{\text {clear } ; i, j}$ is the coagulation kernel between bins $i$ and $j$ in the clear portion of the grid box, $K_{\text {cloudy; } i, j}$ is the coagulation kernel between bins $i$ and $j$ in the cloudy portion of the grid box, $N_{i}$ is the number concentration of particles in bin $i$, and $N_{j}$ is the number concentration of particles in bin $j$.

In our base simulations, for comparison, we do not consider Brownian coagulation between interstitial particles and cloud droplets, which is equivalent to assuming the $f_{\text {cloudy }}$ is 0 in Eq. (1). $K_{\text {cloudy } ; i, j}$ is determined by the size of the interstitial and activated particles, which we vary between sensitivity simulations and are discussed next. We apply this interstitial coagulation mechanism only when temperatures are above $238 \mathrm{~K}$ (threshold for homogeneous freezing; Koop 
Table 1. Summary of simulations.

\begin{tabular}{|c|c|c|c|c|}
\hline Simulation name & $\begin{array}{l}\text { Interstitial } \\
\text { coagulation }\end{array}$ & $\begin{array}{l}\text { Critical diameter } \\
\text { for activation }\end{array}$ & $\begin{array}{l}\text { Assumed droplet } \\
\text { diameter }\end{array}$ & $\begin{array}{l}\text { Minimum } \\
\text { temperature for } \\
\text { use of revised } \\
\text { coagulation }\end{array}$ \\
\hline BASE & No & N/A & N/A & N/A \\
\hline INT_65nm_10um_238K & Yes & $65 \mathrm{~nm}$ & $10 \mu \mathrm{m}$ & $238 \mathrm{~K}$ \\
\hline INT_65nm_13 $\mu \mathrm{m} \_238 \mathrm{~K}$ & Yes & $65 \mathrm{~nm}$ & $13 \mu \mathrm{m}$ & $238 \mathrm{~K}$ \\
\hline INT_40nm_10 & Yes & $40 \mathrm{~nm}$ & $10 \mu \mathrm{m}$ & $238 \mathrm{~K}$ \\
\hline INT_65nm_10 & Yes & $65 \mathrm{~nm}$ & $10 \mu \mathrm{m}$ & $258 \mathrm{~K}$ \\
\hline
\end{tabular}

et al., 2000) because the crystal size distributions and concentrations in ice clouds are much more variable than those of liquid clouds. As glaciation often occurs at warmer temperatures, we perform a sensitivity simulation to this temperature cutoff, described below. We justify this temperature threshold since super-cooled liquid clouds can exist at temperatures as cold as $238 \mathrm{~K}$, although the onset of glaciation can occur at temperatures as warm as 258-263 K (Rosenfeld and Woodley, 2000; Rosenfeld et al., 2011). Recent studies indicate that low-level liquid clouds are ubiquitous in all seasons in remote regions such as the Arctic (e.g., Cesana et al., 2012). Thus, we also perform a simulation where we limit interstitial coagulation to temperatures warmer than $258 \mathrm{~K}$.

\subsection{Simulations}

Table 1 summarizes the simulations performed for this paper. As stated earlier, in our BASE simulation there is no interstitial coagulation by aerosols of cloud droplet size, and the coagulation scheme for the entire grid box assumes all particles are of non-activated size $\left(K_{\text {clear } ; i, j}\right)$. In the INT_65nm_10 $\mathrm{m} \_238 \mathrm{~K}$ simulation, all particles with dry diameters larger than $65 \mathrm{~nm}$ in the cloudy fraction of grid boxes warmer than $238 \mathrm{~K}$ are assumed to have wet diameters of $10 \mu \mathrm{m}$ (i.e., the critical diameter for activation is $65 \mathrm{~nm}$, and the cloud droplet diameter is $10 \mu \mathrm{m}$ for all droplets). $K_{\text {cloudy } ; i, j}$ is calculated using this new wet diameter for the particles with dry diameters larger than the critical $65 \mathrm{~nm}$ value. Thus, the coagulation rate between any two particles, both with dry diameters smaller than $65 \mathrm{~nm}$, remains unchanged from the clear-sky value. For clouds colder than $238 \mathrm{~K}$, we do not consider interstitial coagulation. We test the sensitivity of our results of this temperature cutoff as well as the critical activation dry diameter and the assumed cloud droplet diameter. In the INT_65nm_13 $\mu \mathrm{m} \_238 \mathrm{~K}$ simulation, particles in the cloudy fraction of the grid box with dry diameters larger than $65 \mathrm{~nm}$ are assumed to have wet diameters of $13 \mu \mathrm{m}$. In the INT_40nm_10 $\mathrm{m} \_238 \mathrm{~K}$ simulation, particles in the cloudy fraction of the grid box with dry diameters larger than $40 \mathrm{~nm}$ are assumed to have wet diameters of $10 \mu \mathrm{m}$. Finally, in the INT_65nm_10 $10 \mathrm{~m} \_258 \mathrm{~K}$ simulation, interstitial scavenging is only considered in clouds warmer than $258 \mathrm{~K}$.

None of these simulations capture the variability in clouds throughout the globe (e.g., minimum activation diameters, cloud droplet sizes, glaciation temperatures); however, in this work, we are attempting to bound the aerosol and climate effects of interstitial scavenging that are frequently overlooked in aerosol simulations.

\subsection{Radiative forcing calculations}

The direct radiative effect (DRE) is calculated using the parameterization of Chylek and Wong (1995), which uses the single-scatter approximation. Optical properties for aerosols are calculated from monthly averaged GEOSChem-TOMAS aerosol number and mass size distributions with refractive indices for each aerosol species from the Global Aerosol Data Set (GADS) (Koepke et al., 1997; d'Almedia et al., 1991). We calculate the direct radiative effect assuming the particles are internally mixed, and scattering species (e.g., sulfate and organics) form a shell around black carbon (core-shell assumption). We volume weight the refractive index of the scattering species. Scattering and absorption efficiencies and the asymmetry parameter were calculated using the Bohren and Huffman (1998) coated sphere Mie code (BHCOAT). Surface albedo and cloud fraction are taken as monthly averages from GEOS-5. We assume no aerosol effects in cloudy columns, and our all-sky DRE is the clear-sky DRE multiplied by the clear-sky fraction.

We calculate the cloud-albedo aerosol indirect effect (AIE) offline by calculating a change in monthly averaged cloud reflectivity due to a change in monthly average aerosol number and mass size distributions. We calculate the number of activated particles for each simulation using the Abdul-Razzak and Ghan activation parameterization (AbdulRazzak and Ghan, 2002) and assuming a constant updraft velocity of $0.2 \mathrm{~m} \mathrm{~s}^{-1}$. Cloud optical depth is then calculated using monthly averaged activated particle concentrations, and the monthly averaged liquid water content in the mean cloudy fraction of each grid box from the GEOS5 met fields. Cloud reflectivity is calculated from the cloud optical depth using the two-stream approximation assuming a 
Table 2. Summary of the global mean change in aerosol number $\left(N_{10}\right.$ and $\left.N_{80}\right)$ and the radiative effect for all sensitivity simulations versus the base case.

\begin{tabular}{|c|c|c|c|}
\hline Simulation name & $N_{10} 2 \mathrm{~km}$ (new-BASE) & $N_{80} 2 \mathrm{~km}$ (new-BASE) & AIE (new-BASE) \\
\hline INT_65nm_10um_238K & $-18.4 \%$ & $-10.2 \%$ & $+1.02 \mathrm{~W} \mathrm{~m}^{-2}$ \\
\hline INT_65nm_13 & $-20.8 \%$ & $-11.7 \%$ & $+1.18 \mathrm{~W} \mathrm{~m}^{-2}$ \\
\hline INT_40nm_10 & $-21.3 \%$ & $-10.9 \%$ & $+1.25 \mathrm{~W} \mathrm{~m}^{-2}$ \\
\hline INT_65nm_10 & $-15.0 \%$ & $-10.5 \%$ & $+0.48 \mathrm{~W} \mathrm{~m}^{-2}$ \\
\hline
\end{tabular}

non-absorbing, horizontally homogenous cloud (Lacis and Hansen, 1974), which may lead to an overprediction of cloud albedo of as much as $10 \%$ (Oreopoulis et al., 2007). The change in cloud-albedo forcing for two simulations is then the product of the change in total albedo, incoming solar radiation, cloud area, surface albedo, and atmospheric transmittance (Lacis and Hansen, 1974).

While both our DRE and AIE calculations include simplifying assumptions (e.g., monthly mean aerosol and cloud fields, a single-scatter approximation for DRE, and no DRE in cloudy columns), these calculations should be sufficient for determining the general range of DRE and AIE changes that are expected from inclusion of coagulation of interstitial particles by cloud droplets. These simplified calculations allow us to determine if the interstitial scavenging is important in shaping radiative effects.

\section{Results}

\subsection{Sensitivity of aerosols and radiative forcing to interstitial scavenging}

Table 2 shows the global, $2 \mathrm{~km}$ altitude and annual-mean relative changes in $N_{10}$ and $N_{80}$ (the number concentration of particles larger than 10 and $80 \mathrm{~nm}$, respectively) and absolute changes of the AIE between the various interstitial scavenging simulations and BASE simulation. The $2 \mathrm{~km}$ layer is shown here as being representative of low-level clouds. The global-mean changes in $N_{10}$ and $N_{80}$ are -18.4 and $-10.2 \%$, respectively, between INT_65nm_10 $\mu \mathrm{m} \_238 \mathrm{~K}$ and BASE. Thus, not only are particles with dry diameters smaller than the $65 \mathrm{~nm}$ activation cutoff being reduced in concentration due to interstitial scavenging, particles larger than this (e.g., $N_{80}$ ) are also being reduced in concentration. In clouds, the coagulation rate between the particles with diameters larger than $65 \mathrm{~nm}$ would be slower than outside of the cloud because we only consider Brownian coagulation and we assume all cloud droplets have the same diameter (uniform sizes leads to reduced coagulation rates compared to polydisperse sizes). Thus, the reduction in $N_{80}$ is due to a reduction of the number of particles with dry diameters smaller than $65 \mathrm{~nm}$ and a subsequent reduction of the number of particles growing from these smaller sizes to $80 \mathrm{~nm}$ through condensation growth.
Figure 1 shows the spatial patterns of annualmean changes in $N_{10}$ and $N_{80}$ between the INT_65nm_10 $\mu \mathrm{m} \_238 \mathrm{~K}$ simulation and the BASE simulation. Figure 1a shows the change in $N_{10}$ in the $2 \mathrm{~km}$ layer of the model (to represent the boundary layer). The largest changes are in remote regions with low aerosol source strengths (e.g., the Arctic and extratropical oceans) where the reductions in $N_{10}$ exceed $25 \%$. There are some regions with little $(<1 \%)$ change in $N_{10}$. These are generally in regions of low cloud-cover amount that are downwind of cloudier regions. There is enhanced nucleation in these low cloud-cover-amount regions due to a lower condensation sink advecting in from cloudier regions upwind. Figure 1c shows that the zonal changes in $N_{10}$ are larger than $10 \%$ throughout nearly all of the troposphere. Figure $1 \mathrm{~b}$ shows the $2 \mathrm{~km}$ changes in $N_{80} . N_{80}$ are reduced by over $1 \%$ over the entire $2 \mathrm{~km}$ layer due to interstitial scavenging, and are greater than $5 \%$ in regions outside of the tropical continental regions. Decreases exceed $10 \%$ in remote midlatitude and polar regions. The decreases in the Arctic exceed $20 \%$. Figure $1 \mathrm{~d}$ shows that the decreases in $N_{80}$ due to interstitial scavenging are generally between 10 and $20 \%$ in the free troposphere. These decreases in remote regions show that away from sources, the effects of interstitial scavenging on $\mathrm{CCN}$-sized particles might have significant climatic effects.

Figure 2 shows the predicted annual-mean AIE between the INT_65nm_10 $10 \mathrm{~m} \_238 \mathrm{~K}$ simulation and the BASE simulation. The global mean AIE of interstitial scavenging (Table 2) is $+1.02 \mathrm{~W} \mathrm{~m}^{-2}$ between these simulations, showing that the interstitial scavenging causes a reduction in the amount of cooling of the AIE. The AIE of interstitial scavenging is over $+1 \mathrm{~W} \mathrm{~m}^{-2}$ throughout most tropical and midlatitude oceanic regions and over $+1.5 \mathrm{~W} \mathrm{~m}^{-2}$ throughout much of the Northern Hemisphere oceans. There are regions of smaller AIE of interstitial scavenging over continents due to different combinations of (1) bright surfaces (e.g., northern Africa, Middle East, Australia), (2) lower cloud-cover amounts (same regions), and (3) very high $\mathrm{CCN}$ concentrations saturating AIE changes (e.g., China, eastern North America, Europe, southern Africa).

We also calculated the DRE between the INT_65nm_10 $\mu \mathrm{m} \_238 \mathrm{~K}$ simulation and the BASE simulation. The global mean DRE was cooling, but smaller in magnitude than $-0.01 \mathrm{~W} \mathrm{~m}^{-2}$ for all interstitial scavenging 

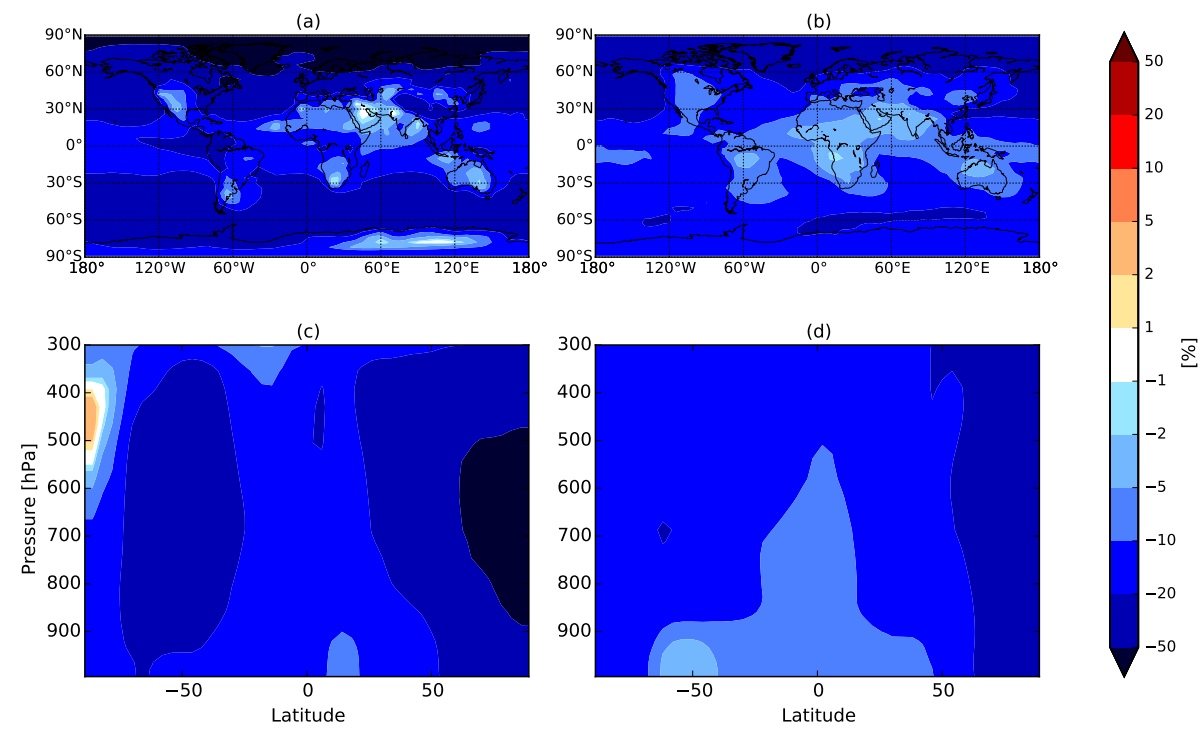

Figure 1. Annual-mean percent changes in $N_{10}$ (a and c) and $N_{80}$ (b and d) changes between INT_80nm_10 (b) show the changes for the $2 \mathrm{~km}$ model layer (representative of low clouds), and (c) and (d) show the zonal-mean changes throughout the troposphere.

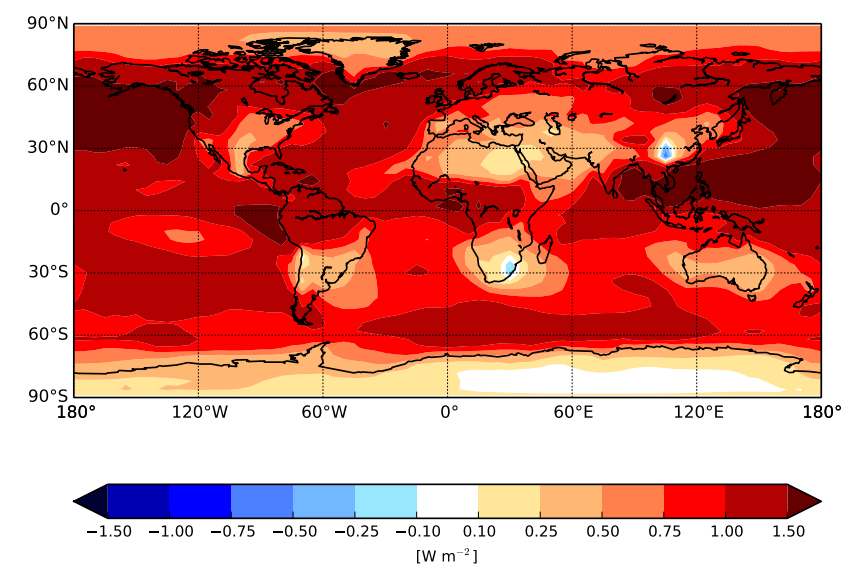

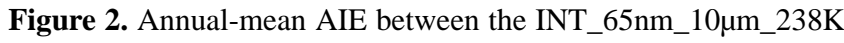
and BASE simulations.

simulations relative to the BASE simulation (not shown due to the small magnitude). The slight cooling was due to a shift in the aerosol mass distribution towards slightly larger sizes due to the enhanced coagulation between the ultrafine particles and the activated particles in clouds. These larger sizes are closer to the peak size of the mass scattering efficiency and thus there is a net negative DRE between the simulations with interstitial scavenging and the BASE simulation (there was also a enhancement in absorption due to the shift in size, but in smaller magnitude to the scattering effect). While there was a large change in $N_{80}$ number concentrations, which greatly affected the AIE, the DRE was largely insensitive to the interstitial scavenging because the changes in mass and mass-scatter/absorption efficiencies were small.

Table 2 also shows the global-mean $N_{10}, N_{80}$ and AIE changes of the interstitial scavenging sensitivity studies versus BASE. We do not show maps for each of these sensitivity cases because the spatial patterns are qualitatively similar to Figs. 2 and 3. Increasing the diameter of the cloud droplets to $13 \mu \mathrm{m}$ (INT_65nm_13 $\mu \mathrm{m} \_238 \mathrm{~K}$ ) leads to $\sim 10$ $20 \%$ strengthening of the decreases in $N_{10}$ and $N_{80}$ and a $15 \%$ strengthening of the increase in AIE difference relative to the case with $10 \mu \mathrm{m}$ cloud droplets. This strengthening of the interstitial scavenging effects is due to enhanced Brownian coagulation rates because of the larger cloud droplets.

Decreasing the activation cutoff diameter to $40 \mathrm{~nm}$ (INT_40nm_10 $\mu$ m_238K) leads to enhanced reduction of N10 relative to the $65 \mathrm{~nm}$ cutoff at the same temperature threshold and cloud droplet size $(-20.8 \%$ rather than $-18.4 \%)$; however, the reduction in N80 is similar to the $65 \mathrm{~nm}$ cutoff $(-10.9 \%$ rather than $-10.2 \%)$. The $40 \mathrm{~nm}$ cutoff means that more particles will activate and participate as scavengers than compared to the simulations with the $65 \mathrm{~nm}$ cutoff; however, the 40-65 nm particles no longer undergo enhanced scavenging. The AIE for the $40 \mathrm{~nm}$ cutoff diameter is about $20 \%$ stronger than in the $65 \mathrm{~nm}$ cutoff case because in many remote locations particles smaller than $80 \mathrm{~nm}$ activate in our AIE calculation.

Increasing the glaciation temperature to $258 \mathrm{~K}$ from $238 \mathrm{~K}$ (INT_65nm_10 $\mu \mathrm{m} \_258 \mathrm{~K}$ ) reduces the effects of the interstitial scavenging because fewer clouds included the interstitial scavenging in the simulation, particularly at high latitudes and altitudes. The magnitude of the AIE for the $258 \mathrm{~K}$ case is roughly half of the AIE from the $238 \mathrm{~K}$ case. Thus, the 

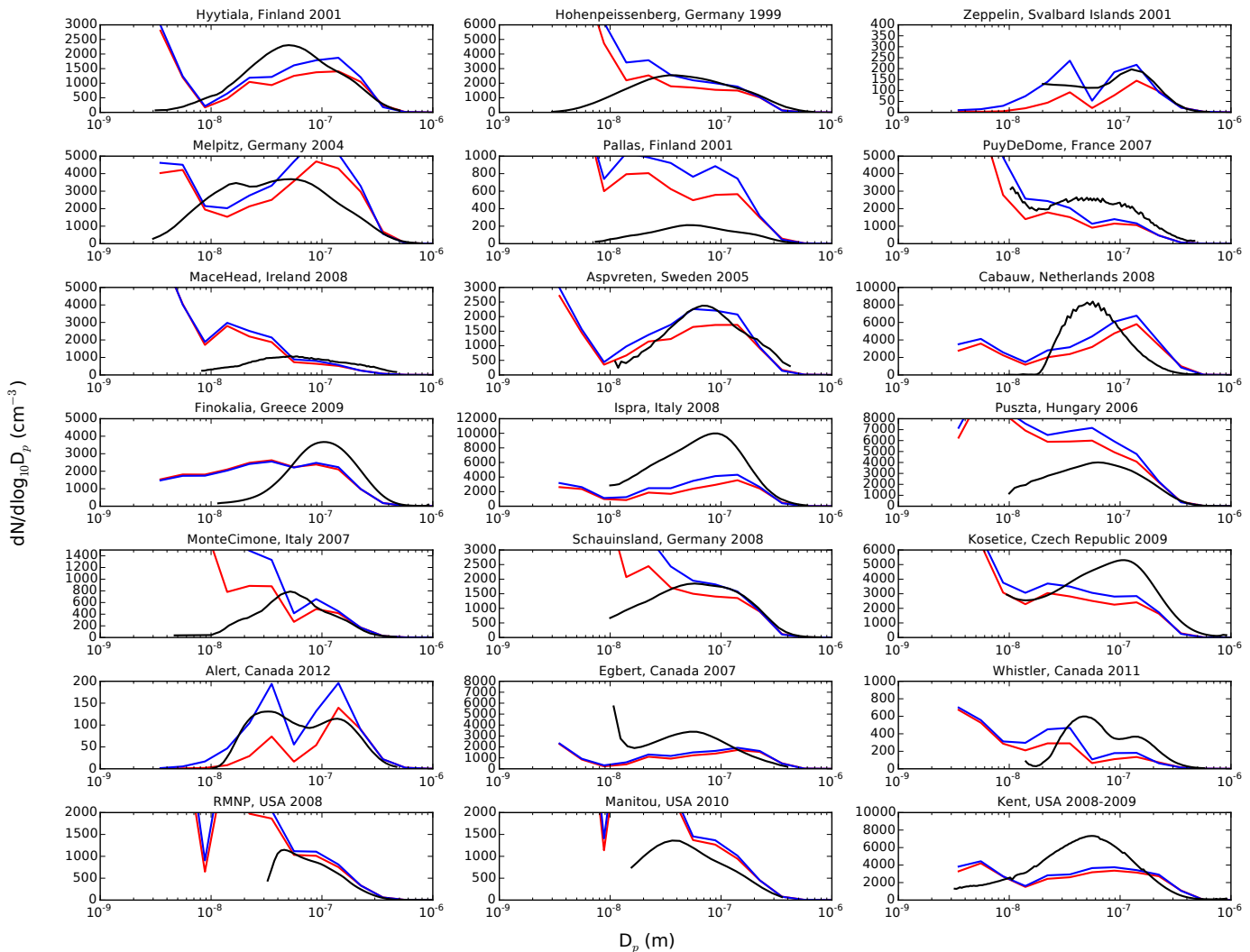

- INT_65nm_10 0 m_238K - BASE - Measurements

Figure 3. Observed and simulated (BASE and INT_65nm_10 $\mu \mathrm{m} \_238 \mathrm{~K}$ ) annual-mean aerosol number size distributions described in D'Andrea et al. (2013).

uncertainties in interstitial scavenging in ice clouds which we ignore here, as well as the temperature at which clouds glaciate, contribute large uncertainties to the strength of interstitial scavenging effects.

Overall, our sensitivity studies show that the interstitial scavenging of particles by cloud drops may reduce aerosol number concentrations by about $10-20 \%$ and decrease the amount of cloud cooling (AIE) by about $1 \mathrm{~W} \mathrm{~m}^{-2}$; however, these magnitudes are uncertain on the order of a factor of 2 due to uncertainties or variability in activation diameter, cloud droplet size, and ice cloud physics.

\subsection{Comparisons to aerosol size-distribution observations}

In this section, we compare our simulations to aerosol sizedistribution measurements to determine how the addition of interstitial scavenging changes model performance. These results should be viewed with caution because aerosol microphysics models may have canceling errors, and improved results may occur for wrong reasons. Nonetheless, this comparison shows how the current state of the model changes relative to observations with the addition of new physics.
For the comparisons, we use long-term (1 year or longer) aerosol size distribution observations from 21 field sites. These data are described in detail in D'Andrea et al. (2013) with a map of the locations in Fig. 1 of that study. The measurements at these sites were from either scanning mobility particle sizers (SMPSs) or differential mobility particle sizers (DMPSs).

Figure 3 shows the annual-mean size distributions at each location for the measurements and the model for the BASE and INT_65nm_10 $\mu \mathrm{m} \_238 \mathrm{~K}$ simulations. The inclusion of interstitial coagulation decreases the number of sub- $100 \mathrm{~nm}$ particles at many remote locations. Figure 4 shows comparisons of modeled to measured annual-mean $N_{10}, N_{40}, N_{80}$ and $N_{150}$ at the 21 sites for each of the five simulations. The statistics of the comparisons are given in Table 3. The statistics are log-mean bias (LMB), slope $(m)$, and coefficient of determination $\left(R^{2}\right)$. We use the coefficient of determination rather than the correlation coefficient $(R)$ because the coefficient of determination quantifies the fraction of the variance in the measurements that is captured by the model. Including interstitial scavenging improves the slope of the comparison of $N_{10}, N_{40}$ and $N_{80}$ to measurements for all four interstitial scavenging simulations relative to the BASE simulation. The predicted concentration of $N_{10}, N_{40}$ and $N_{80}$ in clean re- 

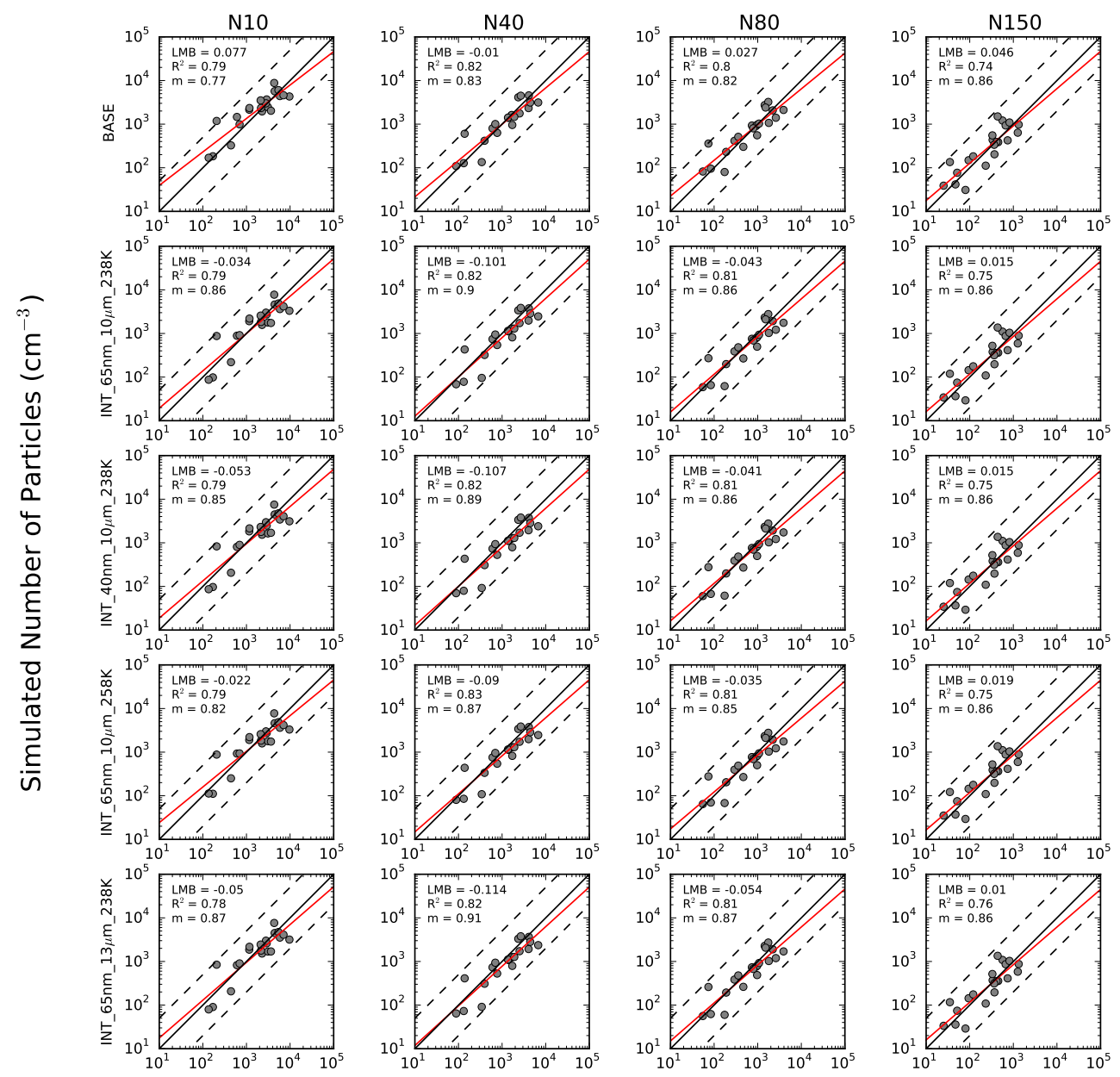

Measured Number of Particles $\left(\mathrm{cm}^{-3}\right)$

Figure 4. Annual-mean $N_{10}, N_{40}, N_{80}$ and $N_{150}$ GEOS-Chem-TOMAS simulation-to-measurement comparisons for the five simulations at the 21 SMPS measurement sites.

gions was, on average, too high in the base simulation, and the interstitial scavenging corrects this to some degree. The INT_65nm_13 $\mu \mathrm{m} \_238 \mathrm{~K}$ simulation, which had the most aggressive interstitial scavenging, had the best slopes for $N_{10}$, $N_{40}$ and $N_{80}$, so it is possible that increasing the rate of interstitial scavenging beyond that of this simulation may further improve the slopes. The slope of the $N_{150}$ relative to measurements does not change because particles with diameters larger than $150 \mathrm{~nm}$ were less affected by the addition of interstitial scavenging than smaller particles (fewer particles grow to $150 \mathrm{~nm}$ than to $80 \mathrm{~nm}$ ).

The inclusion of interstitial scavenging lowers the mean predicted values of $N_{10}, N_{40}, N_{80}$ and $N_{150}$, which means that the LMB has more negative values for the interstitial scavenging simulations relative to BASE. Whether or not interstitial scavenging improves the LMB depends on the LMB of the BASE simulation. The LMB for $N_{10}$ and $N_{150}$ in the BASE simulation are positive, and the inclusion of interstitial scavenging brings the LMB to values closer to zero. For
$N_{40}$ and $N_{80}$, the inclusion of interstitial scavenging brings the LMB to negative values that are further from zero than the BASE simulation. Thus, the inclusion of interstitial scavenging brings the LMB to more negative values, but neither shows a clear improvement or deterioration compared to the BASE simulation. Finally, the inclusion of interstitial scavenging does little to change the scatter across the various sites, so the $R^{2}$ values do not change greatly.

In summary, the inclusion of interstitial scavenging improves the slope of $N_{10}, N_{40}$ and $N_{80}$ comparisons to observations but has little effect on the slope of $N_{150}$ and the LMB and $R^{2}$ of all sizes. Again, the improvement of the slopes shown here could be due to interstitial scavenging canceling errors from elsewhere in the model; however, because interstitial scavenging is a physical processes that was lacking in our model previously, it is encouraging that the model performance improved through its inclusion. 
Table 3. Statistical summary of the comparisons of simulated to measured $N_{10}, N_{40}, N_{80}$ and $N_{150}$ across the 21 sites. Included statistics are log-mean bias (LMB), slope $(m)$, and coefficient of determination $\left(R^{2}\right)$. Bold font indicates the simulation performing best for each statistic.

\begin{tabular}{|c|c|c|c|c|c|c|c|c|c|c|c|c|}
\hline \multirow[t]{2}{*}{ Simulation } & \multicolumn{4}{|c|}{ LMB } & \multicolumn{4}{|c|}{$m$} & \multicolumn{4}{|c|}{$R^{2}$} \\
\hline & $N_{10}$ & $N_{40}$ & $N_{80}$ & $N_{150}$ & $N_{10}$ & $N_{40}$ & $N_{80}$ & $N_{150}$ & $N_{10}$ & $N_{40}$ & $N_{80}$ & $N_{150}$ \\
\hline BASE & 0.077 & -0.01 & 0.027 & 0.046 & 0.77 & 0.83 & 0.82 & 0.86 & 0.79 & 0.82 & 0.80 & 0.74 \\
\hline INT_65nm_10um_238K & -0.034 & -0.101 & -0.043 & 0.015 & 0.86 & 0.90 & 0.86 & 0.86 & 0.79 & 0.82 & 0.81 & 0.75 \\
\hline INT_40nm_10um_238K & -0.053 & -0.107 & -0.041 & 0.015 & 0.85 & 0.89 & 0.86 & 0.86 & 0.79 & 0.82 & 0.81 & 0.75 \\
\hline INT_65nm_10um_258K & -0.022 & -0.09 & -0.035 & 0.019 & 0.82 & 0.87 & 0.85 & 0.86 & 0.79 & 0.83 & 0.81 & 0.75 \\
\hline INT_65nm_13um_238K & -0.05 & -0.114 & -0.054 & 0.010 & 0.87 & 0.91 & 0.87 & 0.86 & 0.78 & 0.82 & 0.81 & 0.76 \\
\hline
\end{tabular}

\section{Conclusions}

In this paper, we test the sensitivity of the global aerosol size distributions and radiative forcing to the scavenging of interstitial aerosol particles by cloud droplets. We limit this study to scavenging in liquid clouds. We make simple assumptions about cloud droplet activation and the size of the cloud droplets as a starting point for understanding the impact of interstitial scavenging. The inclusion of interstitial scavenging was found to decrease the total number of particles larger than $10 \mathrm{~nm}\left(N_{10}\right)$ by $15-21 \%$ at $2 \mathrm{~km}$, relative to a simulation with no interstitial scavenging. The range was due to different simulations where we changed the cutoff temperature for ice clouds, the minimum aerosol activation diameter, and the cloud droplet diameter. The number of particles larger than $80 \mathrm{~nm}\left(N_{80}\right.$, a proxy for $\left.\mathrm{CCN}\right)$ decreased by $10-12 \%$ at $2 \mathrm{~km}$ even though particles of this size were not directly removed by the interstitial scavenging. $N_{80}$ was reduced when interstitial scavenging was included because of fewer particles grew to $80 \mathrm{~nm}$ diameters from smaller sizes. The globalmean aerosol indirect effect of including interstitial scavenging was +0.5 to $+1.3 \mathrm{~W} \mathrm{~m}^{-2}$, but the aerosol direct effect of this process was negligible $\left(\sim-0.01 \mathrm{~W} \mathrm{~m}^{-2}\right)$ because neither the total mass nor the mass-scatter/absorption efficiencies changed.

While the simulations in this paper use simplified assumptions regarding the critical aerosol activation diameter and diameter of cloud droplets, our sensitivity tests show that the scavenging of interstitial particles by cloud droplets yields important $(>10 \%)$ changes in the aerosol size distribution, particularly in remote regions away from sources. These changes provided an improvement in comparison of the simulated aerosol size distribution to SMPS/DMPS measurements at 21 global sites; however, we acknowledge that these improvements could be due to a canceling of other errors in the model. We only consider Brownian coagulation between the interstitial particles and cloud droplets, and we do not consider thermophoresis, diffusiophoresis, turbulence, or electrical effects. These effects are expected to be less important for collection of particles at the size range of the interstitial aerosols.
Thus, while the scavenging of interstitial particles by cloud droplets has often been left out of previous aerosol-climate studies, we recommend aerosol microphysics models include this process since the effects on aerosols and climate are substantial in many global regions. Interstitial scavenging has aerosol-climate effects of similar magnitude as uncertainties in nucleation (Merikanto et al., 2009; Pierce and Adams, 2009; Reddington et al., 2011; Spracklen et al., 2008; Wang and Penner, 2009), primary emissions (Adams and Seinfeld, 2003; Pierce and Adams, 2006, 2009; Reddington et al., 2011; Spracklen et al., 2011), wet/dry deposition (Croft et al., 2012) and other factors (Lee et al., 2013); hence, since significant effort is put into improving these other processes in models, we recommend attention be paid to the coagulation of interstitial particles by cloud droplets. Our simple methods here may be further refined by including online schemes that calculate aerosol activation from updraft velocities and the aerosol size distribution (e.g., Nenes and Seinfeld, 2003; Abdul-Razzak and Ghan, 2000). The MIRAGE and ECHAM-HAM models (Herzog et al., 2004; Ghan et al., 2006; Hoose et al., 2008) already include these online activations schemes as well as the interstitial coagulation described here, so these models may be seen as state-of-the-art for this process.

Acknowledgements. The authors acknowledge Natural Sciences and Engineering Research Council (NSERC) of Canada for funding through the Network on Climate and Aerosols (NETCARE) network. We thank the Atlantic Computational Excellence Network (ACENet) for the computational resources used in this study.

Edited by: L. Zhang

\section{References}

Abdul-Razzak, H. and Ghan, S. J.: A parameterization of aerosol activation: 2. Multiple aerosol types, J. Geophys. Res., 105, 6837, doi:10.1029/1999JD901161, 2000.

Adams, P. J. and Seinfeld, J. H.: Predicting global aerosol size distributions in general circulation models, J. Geophys. Res., 107, 4310-4370, 2002. 
Adams, P. J. and Seinfeld, J. H.: Disproportionate impact of particulate emissions on global cloud condensation nuclei concentrations, Geophys. Res. Lett., 30, 1210-1239, 2003.

Albrecht, B. A.: Aerosols, Cloud Microphysics, and Fractional Cloudiness, Science, 245, 1227-1230, 1989.

Bey, I., Jacob, D. J., Yantosca, R. M., Logan, J. A., Field, B. D., Fiore, A. M., Li, Q. B., Liu, H. G. Y., Mickley, L. J., and Schultz, M. G.: Global modeling of tropospheric chemistry with assimilated meteorology: Model description and evaluation, J. Geophys. Res., 106, 23073-23095, 2001.

Bohren, C. F. and Huffman, D. R.: Appendix B: Coated Sphere, in: Absorption and Scattering of Light by Small Particles, Wiley-VCH Verlag GmbH, Weinheim, Germany, doi:10.1002/9783527618156.app3, 1998.

Boucher, O., Randall, D., Artaxo, P., Bretherton, C., Feingold, G., Forster, P., Kerminen, V.-M., Kondo, Y., Liao, H., Lohmann, U., Rasch, P., Satheesh, S. K., Sherwood, S., Stevens, B., and Zhang, X. Y.: Clouds and Aerosols, in Climate Change 2013: The Physical Science Basis. Contribution of Working Group I to the Fifth Assessment Report of the Intergovernmental Panel on Climate Change, edited by: Stocker, T. F., Qin, D., Plattner, G.-K., Tignor, M., Allen, S. K., Boschung, J., Nauels, A., Xia, Y., Bex, V., and Midgley, P. M., Cambridge University Press, Cambridge, UK and New York, NY, USA, 2013.

Carslaw, K. S., Lee, L. A., Reddington, C. L., Pringle, K. J., Rap, A., Forster, P. M., Mann, G. W., Spracklen, D. V, Woodhouse, M. T., Regayre, L. A., and Pierce, J. R.: Large contribution of natural aerosols to uncertainty in indirect forcing, Nature, 503, 67-71, doi:10.1038/nature12674, 2013.

Cesana, G., Kay, J. E., Chepfer, H., English, J. M., and deBoer, G.: Ubiquitous low-level liquid-containing Arctic clouds: New observations and climate model constraints from CALIPSO-GOCCP, Geophys. Res. Lett., 39, L20804, doi:10.1029/2012GL053385, 2012.

Charlson, R. J., Schwartz, S. E., Hales, J. M., Cess, R. D., Coakley, J. A., Hansen, J. E., and Hofman, D. J.: Climate Forcing by Anthropogenic Aerosols, Science, 255, 423-430, 1992.

Chylek, P. and Wong, J.: Effect of absorbing aerosols on global radiation budget, Geophys. Res. Lett., 22, 929-931, 1995.

Croft, B., Lohmann, U., Martin, R. V., Stier, P., Wurzler, S., Feichter, J., Posselt, R., and Ferrachat, S.: Aerosol size-dependent below-cloud scavenging by rain and snow in the ECHAM5HAM, Atmos. Chem. Phys., 9, 4653-4675, doi:10.5194/acp-94653-2009, 2009.

Croft, B., Pierce, J. R., Martin, R. V., Hoose, C., and Lohmann, U.: Uncertainty associated with convective wet removal of entrained aerosols in a global climate model, Atmos. Chem. Phys., 12, 10725-10748, doi:10.5194/acp-12-10725-2012, 2012.

Croft, B., Pierce, J. R., and Martin, R. V.: Interpreting aerosol lifetimes using the GEOS-Chem model and constraints from radionuclide measurements, Atmos. Chem. Phys., 14, 4313-4325, doi:10.5194/acp-14-4313-2014, 2014.

d'Almedia, G. A., Koepke, P., and Shettle, E. P.: Atmospheric Aerosols: Global Climatology and Radiative Characteristics, A. Deepak Publishing, 561 pp., 1991.

D’Andrea, S. D., Häkkinen, S. A. K., Westervelt, D. M., Kuang, C., Levin, E. J. T., Kanawade, V. P., Leaitch, W. R., Spracklen, D. V., Riipinen, I., and Pierce, J. R.: Understanding global secondary organic aerosol amount and size-resolved condensational behav- ior, Atmos. Chem. Phys., 13, 11519-11534, doi:10.5194/acp-1311519-2013, 2013.

Dockery, D. W., Pope, C. A., Xu, X., Spengler, J. D., Ware, J. H., Fay, M. E., Ferris, B. G., and Speizer, F. E.: An association between air pollution and mortality in six U.S. cities, N. Engl. J. Med., 329, 1753-1759, doi:10.1097/00043764-19950200000008, 1993.

Easter, R. C., Ghan, S. J., Zhang, Y., Saylor, R. D., Chapman, E. G., Laulainen, N. S., Abdul-Razzak, H., Leung, L. R., Bian, X. D., and Zaveri, R. A.: MIRAGE: Model description and evaluation of aerosols and trace gases, J. Geophys. Res., 109, D20210, doi:10.1029/2004JD004571, 2004.

Fuchs, N. A.: Mechanics of Aerosols, Pergamon, New York, 1964. Ghan, S. J., Rissman, T. A., Elleman, R., Ferrare, R. A., Turner, D., Flynn, C., Wang, J., Ogren, J., Hudson, J., Jonsson, H. H., VanReken, T., Flagan, R. C., and Seinfeld, J. H.: Use of in situ cloud condensation nuclei, extinction, and aerosol size distribution measurements to test a method for retrieving cloud condensation nuclei profiles from surface measurements, J. Geophys. Res., 111, D05S10, doi:10.1029/2004JD005752, 2006.

Greenfield, S.: Rain scavenging of radioactive particulate matter from the atmosphere, J. Meteorol., 14, 115-125, 1957.

Hall, W. D.: A detailed microphysical model within a twodimensional dynamic framework: Model description and preliminary results, J. Atmos. Sci., 37, 2486-2507, 1980.

Herzog, M., Weisenstein, D. K., and Penner, J. E.: A dynamic aerosol module for global chemical transport models: Model description, J. Geophys. Res.-Atmos., 109, D18202, doi:10.1029/2003JD004405, 2004.

Hoose, C., Lohmann, U., Bennartz, R., Croft, B., and Lesins, G.: Global simulations of aerosol processing in clouds, Atmos. Chem. Phys., 8, 6939-6963, doi:10.5194/acp-8-6939-2008, 2008.

Koepke, P., Hess, M., Schult, I., and Shettle, E. P.: Global aerosol dataset, Report No. 243, Max-Plank-Institut für Meteorologie, Hamburg, 44 pp., 1997.

Jones, A., Roberts, D. L., Woodage, M. J., and Johnson, C. E.: Indirect sulphate aerosol forcing in a climate model with an interactive sulphur cycle, J. Geophys. Res., 106, 20293-20310, 2001.

Jung, C. H. and Lee, K. W.: Filtration of fine particles by multiple liquid drop and gas bubble systems, Aeros. Sci. Tech., 29, 389 401, 1998.

Kerminen, V. M., Anttila, T., Lehtinen, K. E. J., and Kulmala, M.: Parameterization for atmospheric new-particle formation: Application to a system involving sulfuric acid and condensable watersoluble organic vapors, Aerosol Sci. Tech., 38, 1001-1008, 2004.

Klett, J. D. and Davis, M. H.: Theoretical collision efficiencies of cloud droplets at small Reynolds numbers, J. Atmos. Sci., 30, 107-117, 1973.

Koop, T., Luo, B., Tsias, A., and Peter, T.: Water activity as the determinant for homogeneous ice nucleation in aqueous solutions, Nature, 1, 611-614, 2000.

Lacis, A. A. and Hansen, J.: A Parameterization for the Absorption of Solar Radiation in the Earth's Atmosphere, J. Atmos. Sci., 31, 118-133, doi:10.1175/15200469(1974)031<0118:APFTAO>2.0.CO;2, 1974.

Lee, L. A., Pringle, K. J., Reddington, C. L., Mann, G. W., Stier, P., Spracklen, D. V., Pierce, J. R., and Carslaw, K. S.: The magnitude and causes of uncertainty in global model simulations of 
cloud condensation nuclei, Atmos. Chem. Phys., 13, 8879-8914, doi:10.5194/acp-13-8879-2013, 2013.

Lee, Y. H. and Adams, P. J.: A Fast and Efficient Version of the TwO-Moment Aerosol Sectional (TOMAS) Global Aerosol Microphysics Model, Aerosol Sci. Tech., 46, 678-689, doi:10.1080/02786826.2011.643259, 2012.

Lee, Y. H., Pierce, J. R., and Adams, P. J.: Representation of nucleation mode microphysics in a global aerosol model with sectional microphysics, Geosci. Model Dev., 6, 1221-1232, doi:10.5194/gmd-6-1221-2013, 2013.

Lin, C. L. and Lee, S.: Collision efficiency of water drops in the atmosphere, J. Atmos. Sci., 32, 1412-1418, 1975.

Malm, W. C., Pitchford, M. L., Scruggs, M., Sisler, J. F., Ames, R., Copeland, S., Gebhart, K. A., and Day, D. E.: Spational and Seasonal Patterns and Temporal Variability of Haze and its Constituents in the United States: Report III, Coop. Inst. for Res., Colo. State Univ., 2000.

Mann, G. W., Carslaw, K. S., Spracklen, D. V., Ridley, D. A., Manktelow, P. T., Chipperfield, M. P., Pickering, S. J., and Johnson, C. E.: Description and evaluation of GLOMAP-mode: a modal global aerosol microphysics model for the UKCA composition-climate model, Geosci. Model Dev., 3, 519-551, doi:10.5194/gmd-3-519-2010, 2010.

Mann, G. W., Carslaw, K. S., Ridley, D. A., Spracklen, D. V., Pringle, K. J., Merikanto, J., Korhonen, H., Schwarz, J. P., Lee, L. A., Manktelow, P. T., Woodhouse, M. T., Schmidt, A., Breider, T. J., Emmerson, K. M., Reddington, C. L., Chipperfield, M. P., and Pickering, S. J.: Intercomparison of modal and sectional aerosol microphysics representations within the same 3-D global chemical transport model, Atmos. Chem. Phys., 12, 4449-4476, doi:10.5194/acp-12-4449-2012, 2012.

Merikanto, J., Spracklen, D. V., Mann, G. W., Pickering, S. J., and Carslaw, K. S.: Impact of nucleation on global CCN, Atmos. Chem. Phys., 9, 8601-8616, doi:10.5194/acp-9-8601-2009, 2009.

Napari, I., Noppel, M., Vehkamaki, H., and Kulmala, M.: Parametrization of ternary nucleation rates for $\mathrm{H}_{2} \mathrm{SO}_{4}-\mathrm{NH}_{3}-$ $\mathrm{H}_{2} \mathrm{O}$ vapors, J. Geophys. Res., 107, 4310-4381, 2002.

Nenes, A. and Seinfeld, J. H.: Parameterization of cloud droplet formation in global climate models, J. Geophys. Res., 108, 4415, doi:10.1029/2002JD002911, 2003.

Oreopoulis, L., Cahalan, R. F., and Platnick, S.: The Plane-Parallel Albedo Bias of Liquid Clouds from MODIS Observations, J. Climate, 20, 5114-5125, doi:10.1175/JCLI4305.1, 2007.

Pierce, J. R. and Adams, P. J.: Global evaluation of CCN formation by direct emission of sea salt and growth of ultrafine sea salt, J. Geophys. Res., 111, D06203, doi:10.1029/2005JD006186, 2006.

Pierce, J. R. and Adams, P. J.: Efficiency of cloud condensation nuclei formation from ultrafine particles, Atmos. Chem. Phys., 7, 1367-1379, doi:10.5194/acp-7-1367-2007, 2007.

Pierce, J. R. and Adams, P. J.: Uncertainty in global CCN concentrations from uncertain aerosol nucleation and primary emission rates, Atmos. Chem. Phys., 9, 1339-1356, doi:10.5194/acp-91339-2009, 2009.

Pierce, J. R., Evans, M. J., Scott, C. E., D’Andrea, S. D., Farmer, D. K., Swietlicki, E., and Spracklen, D. V.: Weak global sensitivity of cloud condensation nuclei and the aerosol indirect effect to Criegee $+\mathrm{SO}_{2}$ chemistry, Atmos. Chem. Phys., 13, 3163-3176, doi:10.5194/acp-13-3163-2013, 2013.
Pruppacher, H. R. and Klett, J. D.: Microphysics of Clouds and Precipitation, 2nd Edn., Kluwer Academic Publishers, Dordrecht, the Netherlands, 1997.

Reddington, C. L., Carslaw, K. S., Spracklen, D. V., Frontoso, M. G., Collins, L., Merikanto, J., Minikin, A., Hamburger, T., Coe, H., Kulmala, M., Aalto, P., Flentje, H., Plass-Dülmer, C., Birmili, W., Wiedensohler, A., Wehner, B., Tuch, T., Sonntag, A., O’Dowd, C. D., Jennings, S. G., Dupuy, R., Baltensperger, U., Weingartner, E., Hansson, H.-C., Tunved, P., Laj, P., Sellegri, K., Boulon, J., Putaud, J.-P., Gruening, C., Swietlicki, E., Roldin, P., Henzing, J. S., Moerman, M., Mihalopoulos, N., Kouvarakis, G., Ždímal, V., Zíková, N., Marinoni, A., Bonasoni, P., and Duchi, R.: Primary versus secondary contributions to particle number concentrations in the European boundary layer, Atmos. Chem. Phys., 11, 12007-12036, doi:10.5194/acp-11-12007-2011, 2011.

Rogers, R. R. and Yau, M. K.: A Short Course in Cloud Physics, 3rd Edn., Butterworth-Heinmann, Oxford, UK., 1989.

Rosenfeld, D. and Woodley, W. L.: Deep convective clouds with sustained supercooled liquid water down to $-37.5^{\circ} \mathrm{C}, 405,23-$ 25, 2000.

Rosenfeld, D., Yu, X., Liu, G., Xu, X., Zhu, Y., Yue, Z., Dai, J., Dong, Z., Dong, Y., and Peng, Y.: Glaciation temperatures of convective clouds ingesting desert dust, air pollution and smoke from forest fires, Geophys. Res. Lett., 38, L21804, doi:10.1029/2011GL049423, 2011.

Schlamp, R. J., Grover, S. N., and Pruppacher, H. R.: A numerical investigation of the effect of electric charges and vertical external electric fields on the collision efficiency of cloud drops, J. Atmos. Sci., 33, 1747-1755, 1976.

Seinfeld, J. H. and Pandis, S. N.: Atmospheric Chemistry and Physics, 1st Edn., John Wiley and Sons, New York, 2006.

Slinn, W. G. N.: Precipitation Scavenging in Atmospheric Science and Power Production, Ch. 11, edited by: Randerson, D., Tech. Inf. Cent., Off. of Sci. and Techn. Inf., Dep. of Energy, Washington DC, USA, 466-532, 1984.

Spracklen, D. V., Pringle, K. J., Carslaw, K. S., Chipperfield, M. P., and Mann, G. W.: A global off-line model of sizeresolved aerosol microphysics: I. Model development and prediction of aerosol properties, Atmos. Chem. Phys., 5, 22272252, doi:10.5194/acp-5-2227-2005, 2005a.

Spracklen, D. V., Pringle, K. J., Carslaw, K. S., Chipperfield, M. P., and Mann, G. W.: A global off-line model of size-resolved aerosol microphysics: II. Identification of key uncertainties, Atmos. Chem. Phys., 5, 3233-3250, doi:10.5194/acp-5-3233-2005, 2005b.

Spracklen, D. V, Carslaw, K. S., Kulmala, M., Kerminen, V. M., Sihto, S. L., Riipinen, I., Merikanto, J., Mann, G. W., Chipperfield, M. P., Wiedensohler, A., Birmili, W., and Lihavainen, H.: Contribution of particle formation to global cloud condensation nuclei concentrations, Geophys. Res. Lett., 35, D06808, doi:10.1029/2007GL033038, 2008.

Spracklen, D. V., Carslaw, K. S., Pöschl, U., Rap, A., and Forster, P. M.: Global cloud condensation nuclei influenced by carbonaceous combustion aerosol, Atmos. Chem. Phys., 11, 9067-9087, doi:10.5194/acp-11-9067-2011, 2011.

Stevens, R. G. and Pierce, J. R.: The contribution of plume-scale nucleation to global and regional aerosol and CCN concentrations: evaluation and sensitivity to emissions changes, Atmos. Chem. Phys., 14, 13661-13679, doi:10.5194/acp-14-13661-2014, 2014. 
Trivitayanurak, W., Adams, P. J., Spracklen, D. V., and Carslaw, K. S.: Tropospheric aerosol microphysics simulation with assimilated meteorology: model description and intermodel comparison, Atmos. Chem. Phys., 8, 3149-3168, doi:10.5194/acp-83149-2008, 2008.

Twomey, S.: Pollution and the Planetary Albedo, Atmos. Environ., 8, 1251-1256, 1974.

Vehkamäki, H., Kulmala, M., Napari, I., Lehtinen, K. E. J., Timmreck, C., Noppel, M., and Laaksonen, A.: An improved parameterization for sulfuric acid-water nucleation rates for tropospheric and stratospheric conditions, J. Geophys. Res., 107, 4610-4622, 2002.

Wang, M. and Penner, J. E.: Aerosol indirect forcing in a global model with particle nucleation, Atmos. Chem. Phys., 9, 239-260, doi:10.5194/acp-9-239-2009, 2009.

Wang, P. K., Grover, S. N., and Pruppacher, H. R.: On the effect of electric charges on the scavenging of aerosol particles by clouds and small raindrops, J. Atmos. Sci., 35, 1735-1743, 1978.

Wang, X., Zhang, L., and Moran, M. D.: Development of a new semi-empirical parameterization for below-cloud scavenging of size-resolved aerosol particles by both rain and snow, Geosci. Model Dev., 7, 799-819, doi:10.5194/gmd-7-799-2014, 2014.
Westervelt, D. M., Pierce, J. R., Riipinen, I., Trivitayanurak, W., Hamed, A., Kulmala, M., Laaksonen, A., Decesari, S., and Adams, P. J.: Formation and growth of nucleated particles into cloud condensation nuclei: model-measurement comparison, Atmos. Chem. Phys., 13, 7645-7663, doi:10.5194/acp-13-76452013, 2013.

Westervelt, D. M., Pierce, J. R., and Adams, P. J.: Analysis of feedbacks between nucleation rate, survival probability and cloud condensation nuclei formation, Atmos. Chem. Phys., 14, 5577 5597, doi:10.5194/acp-14-5577-2014, 2014.

Yu, F.: A secondary organic aerosol formation model considering successive oxidation aging and kinetic condensation of organic compounds: global scale implications, Atmos. Chem. Phys., 11, 1083-1099, doi:10.5194/acp-11-1083-2011, 2011.

Yu, F. and Luo, G.: Simulation of particle size distribution with a global aerosol model: contribution of nucleation to aerosol and CCN number concentrations, Atmos. Chem. Phys., 9, 76917710, doi:10.5194/acp-9-7691-2009, 2009.

Zhang, L., Wang, X., Moran, M. D., and Feng, J.: Review and uncertainty assessment of size-resolved scavenging coefficient formulations for below-cloud snow scavenging of atmospheric aerosols, Atmos. Chem. Phys., 13, 10005-10025, doi:10.5194/acp-13-10005-2013, 2013. 